\title{
LA POLÍTICA SOCIAL EN LA CRISIS : UNA ALTERNATIVA PARA EL SECTOR SALUD ${ }^{(*)}$
}

\author{
Asa Cristina Laurel( $\left.{ }^{\star \star}\right)$
}

Mis agradecimientos a María Elena Ortega por su ayuda en la recolección de la información y por sus estimulantes comentarios.

\section{INTRODUCCIÓN}

La crisis y sus efectos económicos, políticos y sociales han impulsado la búsqueda de nuevos caminos para salir de ella. La profundidad de la crisis y de los desacuerdos sobre cómo transformar la sociedad han llevado a una nueva conformación de fuerzas políticas, cada una con su propio proyecto de nación. Es decir, la complejidad de la realidad presente y la radicalidad de los cambios requeridos obligan a hacer propuestas de transformación que engloban todos los aspectos de la vida nacional. Sin embargo, en la discusión de estos proyectos los problemas

$\left(^{\star}\right)$ O presente texto foi transcrito, com autorizaço da autora, de Documentos de Trabajo, $n^{\circ} 27$, Fundación Friederich Ebert, México, 1991 (Nota dos Editores).

(**) Docente del Departamento de Maestria Social, Universidad Autónoma Metropolitana - Xochimilco 
económicos y políticos han sido dominantes a pesar de que la agudización de las condiciones sociales, tal vez, es el rasgo más dramático de la crisis.

El presente trabajo pretende abordar un aspecto de la cuestión social que es la política de salud. Concebimos a la política sanitaria como parte de la política social que, a su vez, guarda una relación estrecha con la política económica en el marco de un proyecto nacional. Por ello, el análisis de la política de salud permite desentranr en un terreno particular cómo se expresan esos proyectos. Hoy en México los distintos proyectos no son sólo proyectos ideológico-políticos que se enfrentan en el terreno de las ideas sino que se trata de proyectos llevados por fuerzas políticas que se disputan la conducción de la sociedad en el momento presente. Por ello, estos proyectos tienen como punto de partida obligado la situación existente para de allí delinear su concepción del proceso de transformación.

No cabe duda, que el proyecto gubernamental en el terreno económico es un proyecto neoliberal ortodoxo que postula la capacidad de la iniciativa privada y el mercado de resolver la crisis económica. En el terreno social se complementa con un discurso sobre el estado social y solidario. En este respecto es menos transparente ya que no plantea explícitamente una política social neoliberal sino que este discurso reclama que su política preserva el contenido social de la Revolución Mexicana. La hipótesis que se pondrá a prueba es que el discurso social del proyecto gubernamental no corresponde a los hechos y que éstos revelan una alta consistencia interna de su proyecto ya que tanto la política económica como la social descansan sobre los postulados neoliberales. 
El proyecto altenativo emergente descansa sobre las ideas estratégicas de la sobreranía e independencia nacional, la democracia y el crecimiento económico con justicia social. Esto último significa que sus principales objetivos se refieren a la cuestión social y, por ello, la política social tiene un papel central y de conducción del proceso de transformación que además ha de ser democrático, mientras que las polítcas económicas, por así decirlo, sólo son el medio para alcanzar los objetivos sociales de justicia e igualdad. Sin embargo, falta por profundizar y precisar los contenidos más específicos de este proyecto.

En este trabajo, primero, se introduce una discusión suscinta de las distintas concepciones sobre el papel y contenido de las políticas sociales en el proceso social global con el fin de ubicar el proceso mexicano y los distintos proyectos. Luego se hace un diagnóstico de la situación actual de la producción de servicios de salud y de las tendencias que la política de salud del proyecto gubernamental le está imprimiendo. En la parte final se delinea una propuesta alternativa de política de salud que, partiendo de la situación actual y una concepción social de la salud-enfermedad, trata de avanzar hacia la realización de la democracia y la justicia e igualdad social en el cumplimiento del derecho a la salud. 


\section{CONCEPCIONES Y PRÁCTICAS DE POLÍTICA SOCIAL}

La crisis capitalista de los setenta suscitó el cuestionamiento del estado de bienestar o, lo que es lo mismo, de las políticas sociales del capitalismo avanzado. Conviene senlar que se convirtió en un punto central de discusión porque el estado de bienestar, bajo una $u$ otra forma, era una realidad presente en todas estas sociedades. Con la emergencia de la Nueva Derecha, el centro de la discusión se desplaza del debate sobre el contenido y la forma de las políticas sociales en el marco del estado de bienestar a una crítica global de éste. Se da pues una nueva polarización entre la posición neoliberal, abierta y agresivamente contraria al estado de bienestar, y todas las demás que lo aceptan, desde las posiciones con reservas hasta las entusiastas.

\section{EL NEOLIBERALISMO Y EL ESTADO ASISTENCIALISTA}

El rechazo de los neoliberales o "anti-colectivistas" ${ }^{1}$ - representados por Hayek y Friedman - al estado de bienestar se deriva de los valores que sustenta esta concepción ideológica, a saber, la libertad individual y la desigualdad. Es abiertamente anti-igualitarista ya que postula que la competencia individual en el mercado libre corrige todos los males económicos y sociales y que la desigualdad es la fuerza motora 
de la competencia e iniciativa individual. Además, considera que la democracia es problemática porque en las sociedades parlamentarias genera "grupos de interés" que formulan demandas y votan en función de la promesa de su satisfacción lo que tiende a incrementar la intervención gubernamental y estatal restringiendo el libre mercado y la iniciativa individual.

El antiestatismo de los neoliberales sigue de su veneración por el individualismo, la competencia y el mercado. Sin embargo, habría que aclarar que propugnan por un Estado fuerte en términos de que garantiza el marco legal y las condiciones adecuadas para el libre mercado. Su antiestatismo consiste, por una parte, en limitar la acción estatal en la economía, tanto en su planeación y conducción como en cuanto agente económico directo, $y$, por el otro, en reducir sus funciones relacionadas con el bienestar social.

Los neoliberales plantean alcanzar el bienestar social estimulando las acciones de la familia, la comunidad y los servicios privados que para ellos son las fuentes "naturales" del bienestar social. Por ello, el Estado sólo debe actuar cuando estos actores fallan y garantizan un mínimo para aliviar la pobreza y producir los servicios que los privados no pueden o quieren producir. Propugnan, pues, un estado asistencialista y no de bienestar. En el terreno particular de la salud rechazan la producción pública de servicios de salud gratuitos.

Las estrategias neoliberales ${ }^{2}$ para reducir la acción estatal en el terreno del bienestar social son la privatización de la producción de servicios; el recorte del gasto social eliminando programas y reduciendo beneficios; la focalización del gasto, 
- sea, derivándolo a los grupos más pobres introduciendo mecanismos de comprobación de su pobreza (means testing); y la descentralización de los servicios hacia el nivel local.

\section{EL ESTADO COMO GARANTE DE UN MÍNIMO DE BIENESTAR SOCIAL}

El bloque defensor o promotor del Estado de bienestar puede, esquemáticamente, ser dividido en dos grandes posiciones, a saber, los "colectivistas renuentes" y los "Fabianos". Los primeros, cuyos representantes más conocidos son Keynes, Beveridge y Galbright y cuya expresión política es la social democracia conservadora, suscriben los valores de la libertad individual, el individualismo y la empresa privada competitiva pero son ante todo pragmáticos. ${ }^{3}$ Creen que el capitalismo es el mejor sistema económico pero no que se auto-regula. Por razones económicas de acumulación y políticas de legitimidad el Estado debe asumir una función reguladora. De allí sus políticas económicas de planeación, generación de demanda y anticíclicas.

Aceptan la acción estatal en el terreno del bienestar social en cuanto confieren al Estado la responsabilidad de tender una red de seguridad contra la privación social y garantizar un esquema básico de bienestar para los individuos. Este se concibe a veces como un mínimo social y a veces en función de la pobreza relativa de los grupos "subprivilegiados". Plantean que el elemento para juzgar si una sociedad 
es justa no es su grado de igualdad sino cuál es la suerte de los pobres. ${ }^{4}$ Esta posición, por tanto, no se guía por criterios de universalidad e igualdad en la formulación de las políticas sociales. Propone un esquema de seguro que se basa inicialmente en un elemento de voluntad y responsabilidad individual apoyado con un esquema estatal básico pero comprensivo. Son elementos del esquema básico un servicio nacional de salud, la protección familiar, las políticas de pleno empleo; y la educación básica que, sin embargo, es vista como una inversión productiva.

Fiel a su idea de economía mixta la extiende al terreno del bienestar social aceptando un esquema mixto público-privado de seguros y producción de servicios. Es decir, no tienen objeciones de principio a la presencia privada en este campo sino sólo pragmáticas referidas a los costos y la eficiencia-eficacia. En el debate de los últimos ans han introducido consideraciones sobre la necesidad de descentralizar y democratizar la planeación y el control de las acciones públicas de bienestar y reducir el papel del gobierno central a la provisión de los servivios sociales.

\section{LOS DERECHOS SOCIALES, EL BIEN COLECTIVO Y LA IGUALDAD}

La segunda gran posición dentro del bloque defensor del Estado de bienestar agrupa a aquellos que lo abrazan sin reservas en el marco de los valores del bien colectivo y la igualdad. ${ }^{5}$ Tradicionalmente los representantes de esta posición 
han sido los llamados Fabianos y sus expresiones políticas de las distintas corrientes de la socialdemocracia progresista y del socialismo democrático parlamentario.

A partir del ataque neoliberal al Estado de bienestar buena parte de los marxistas y los socialistas revolucionarios han pasado de posiciones de crítica a los contenidos políticos de legitimación y económicos de acumulación del estado de bienestar a asumir posiciones en su defensa semejantes a las de los Fabianos; cambio explicable en función de la unidad de valores que subyacen a ambas corrientes que esencialmente se distinguían por su estrategia política. ${ }^{6}$ Es decir, mientras los socialistas democráticos veían a la lucha por los derechos sociales como un elemento fundamental en la construcción de las alianzas para llegar a la sociedad socialista por la vía parlamentaria, los socialistas revolucionarios juzgaban poco viable a esta estrategia. $^{6}$

Los valores del bien colectivo y la igualdad llevan a una concepción de bienestar basada en la idea de que la sociedad -la colectividad-debe responsabilizarse de proveer y garantizar un nivel satisfactorio e igual de bienestar social para todos sus miembros. ${ }^{7}$ esta idea está estrechamente vinculada a la idea de los derechos sociales de los ciudadanos que, en la interpretación de Marshall, ${ }^{8}$ se desarrollam como extensión de los derechos ciudadanos legales y políticos. De alli sigue que las políticas sociales deben ser universales -abarcar el conjunto de la población y proveer beneficios iguales para todos- y redistributivas -como mecanismo para disminuir la desigualdad. 
Esta posición sostiene, pues, como principio que la esfera del bienestar social pertenece a la cosa pública y como tal es que-hacer estatal. Por otra parte, en cuanto los derechos sociales significan la satisfacción de ciertos niveles de bienestar, determinados por las condiciones sociales imperantes, no deben restringirse a un mínimo sino que pueden y deben expandirse y garantizar una "Vida Buena". O sea, es ajena a políticas sociales cuya función única es proteger a los individuos contra la indigencia y remediar la pobreza.

Esta concepción confiere tres características importantes a las políticas sociales que se impulsan. ${ }^{9}$ La primera es que promueve programas comprensivos de seguridad social con beneficios universales e iguales para todos lo que significa que no hay un vínculo entre responsabilidad financiera directa y acceso a los beneficios. La segunda es que la política social no es un complemento a la política económica sino uno de sus elementos básicos. ${ }^{10}$ Ejemplo de ello es la política de reestructuración productiva llevado adelante por la socialdemocracia sueca que descansaba sobre una políticia de igualación salarial incrementando los salarios bajos y una política de pleno empleo. Ello lleva a la tercera característica que es que la política social ocupa un lugar central en la estrategia política de poder en tanto constituye uno de los pilares principales de construcción de alianzas sociales. ${ }^{11}$

La revisión de las distintas posiciones respecto a la política social muestra que, en efecto, se pueden distinguir dos grandes posiciones respecto al papel del Estado en ella. La neoliberal que pregona un Estado asistencialista que sólo debe intervenir para aliviar la pobreza con programas mínimos y selectivos, dejando el grueso del bienestar social al mercado y al ámbito de lo privado. Por otro lado tenemos 
las distintas concepciones del Estado de bienestar que se funda en la idea de que toda la población debe gozar de un esquema de seguridad social garantizado por el Estado. Sin embargo, hay una gran distinción importante entre estas concepciones en cuanto una ve al Estado como el garante último de esa seguridad social mientras que la otra la considera una actividad central del Estado. La primera posición se acerca a la neoliberal en cuanto centra su preocupación en aliviar la pobreza. Se basa por ello en criterios selectivos pero propone $-y$ en esto se distingue de la posición neoliberal- programas comprensivos abarcando los distintos terrenos del bienestar social. La otra posición concibe las instituciones del Estado de bienestar en función del cumplimiento de los derechos sociales ciudadanos y como arma para lograr la igualdad. Por ello se basa en criterios de universalidad y redistribución y promueve programas comprensivos que no sólo abarcan un bienestar social mínimo sino todos los aspectos que garantizan la igualdad de condiciones para todos.

Finalmente resulta importante enfatizar el carácter principalmente ideológico del debate y la confrontación entre la Nueva Derecha y los defensores del estado de bienestar en los países de capitalismo avanzado, ya que tuvo pocas repercusiones prácticas en el terreno concreto de las políticas sociales con la posible excepción de los EUA. ${ }^{12}$ Es decir, en términos concretos resultó cierta la irreversibilidad del Estado de bienestar ${ }^{13}$ ya que su desmantelamiento no fue posible, debido a las relaciones de fuerza política; ni legítimo, por la popularidad de la cual goza también entre los votantes por las opciones de la Nueva Derecha. ${ }^{14}$ Aclaremos. Globalmente la política neoliberal ha conllevado un nuevo patrón de "sobre consumosubconsumo"15 con una exclusión social importante, redistribución regresiva del 
ingreso e incremento en la pobreza relativa y absoluta pero no fundamentalmente por la eliminación de las instituciones del Estado de bienestar sino por la política económica y sólo en segunda instancia por ciertos recortes o modificaciones en los programas de protección social. ${ }^{16}$ contrasta con esta situación lo ocurrido en los países latinoamericanos donde el proyecto neoliberal ha sido impuesto tanto en sus vertientes económicas como sociales bajo el auspicio de organismos internacionales.

A pesar del insignificante impacto real del neoliberalismo en la política social de los países capitalistas avanzados es necesario reconocer su inmensa repercusión ideológica que dio carta de naturalidad a valores como el "sano" egoísmo y el darwinismo social. Sin embargo, también es justo reconocer que el debate ha impulsado la discusión sobre problemas reales de las instituciones públicas como son el centralismo, las estructuras burocráticas, el autoritarismo y la antidemocracia imperante en ellas.

\section{POLÍTICA SOCIAL DEL PROYECTO CONSTITUCIONAL O NEOLIBERAL?}

Por los orígenes del Estado mexicano moderno en la primera revolución social del siglo veinte, la idea de los derechos sociales es uno de los ejes principales de la Constitución en cuanto expresión legal del pacto social surgido de la Revolución Mexicana. El texto constitucional consagra, así, los derechos al trabajo, al salario suficiente, a la educación, a la protección de la salud y a la vivienda y son considerados 
como derechos universales de todos los mexicanos. ${ }^{17}$ Con el reconocimiento de estos derechos los lineamentos básicos de la política social son, de hecho, el mandato constitucional. Sin embargo, desde el propio texto constitucional existe ambiguedad porque, con excepción del derecho a la educación, no se establece la obligación del Estado de garantizar el cumplimiento de estos derechos cuya universalidad, por ello, queda como abstracción.

La principal forma que tomaron las instituciones del Estado de bienestar mexicano es los institutos de seguridad social (IMSS y ISSSTE) y de vivienda (INFONAVIT) considerados en al Constitución de utilidad pública y social. ${ }^{18}$ Esta forma significa de entrada que el acceso a los beneficios está condicionado al cumplimiento de la responsabilidad financiera. Este criterio de selectividad tendría una importancia menor si estas instituciones se hubieran universalizado; cuestión que, sin embargo, se ha visto obstaculizada por la estructura de classe y las condiciones de organización popular que han dado por resultado que la seguridad social principalmente abarca a los asalariados organizados sindicalmente. Adicionalmente habría que notar que la cobertura de beneficios que dan el seguro social no es comprensiva. Comparativamente con otros países es más notoria la ausencia de un seguro contra el desempleo, que no sea el de cesantía en edad avanzada, y un esquema comprensivo de protección familiar.

El hecho de que la construcción de las instituciones del Estado de bienestar se da por medio de la seguridad social selectiva ha originado el crecimiento de instituciones paralelas encaminadas a garantizar un mínimo social para la población pobre p. e. en salud y protección familiar. Además, este esquema ha retrasado la 
universalización de beneficios sociales básicos como la jubilación pagada y la protección contra el desempleo.

En resumen se puede decir que el ideario constitucional del Estado de bienestar mexicano pertenece a las corrientes progresistas de la materia en cuanto se basa en el reconocimiento de los derechos sociales ciudadanos. Sin embargo, en la práctica se presenta una dualidad en las políticas sociales, que lejos de ser universales y comprensivas, han sido segmentadas y selectivas en función de las distintas clases y fracciones de clase. Así, por un lado, los esquemas de seguridad social garantizan beneficios iguales para todos los asegurados que van más allá de um mínimo social, mientras que, por el otro, las instituciones y políticas públicas no paraestatales ni siquiera ofrecen la protección social mínima. Este patrón, asimismo, deja un espacio importante de producción mercantil de servicios, que sólo en el caso de la educación se considera concesión estatal con carácter revocable. ${ }^{19}$ Finalmente, es importante rescatar que el cumplimiento de los derechos al trabajo y al salario suficiente no se ha perseguido por vía de la política social propiamente hablando sino como parte de la política económica.

Esta conformación, ambigua e imperfecta, del estado de bienestar genera condiciones que permiten que se puede dar una regresión relativamente rápida hacia un estado asistencialista ${ }^{20}$ bajo determinadas condiciones políticas, aunque ello ocurra como violación flagrante del mandato constitucional y en contra de la voluntad popular. Una regresión con estas características es lo que hoy se está dando con la imposición del proyecto gubernamental. 
Los elementos que permiten afirmar que esto esta ocurriendo son varios. Así, en los planes gubernamentales ${ }^{21}$ el cumplimiento de los derechos sociales centrales del artículo 123 constitucional -el derecho al trabajo y al salario mínimo suficiente- está explícitamente subordinado a la dinámica económica basada en la inversión privada; cuestión seria ya que, en el supuesto de que este plan funcionara, datos del Banco de México y Mafinsa 22 demuestran que no se generarián los empleos necesarios para satisfazer la nueva demanda de puestos de trabajo en este sexenio y menos para acabar con el rezago de 8 millones de empleos. Asimismo, para el 2005 los salarios habrían recuperado la mitad del poder de compra perdido a partir de $1977 .{ }^{23}$ Además, está anunciado un cambio en la legislación laboral ${ }^{24}$ que legitimaría la sujección del empleo y el salario a las fuerzas del libre mercado.

Referente a los derechos a la educación y a la protección de la salud el recorte del gasto social, la implantación de nuevos esquemas de financiamento, los cambios legislativos recientes, el reordenamiento institucional de acuerdo con las directrices de los organismos financieros internacionales, el deterioro de las instituciones públicas, el peso de la producción privada de estos servicios y la creación y énfasis en el Pronasol apoyan la hipótesis de que hay un viraje hacia una política asistencialista en este terreno.

Hay que recordar que ello ocurre en una situación social grave, como el resultado de la crisis y de siete años de aplicación de la política neoliberal, que se caracteriza por la agudización de la desigualdad social, niveles altísimos de desempleo y redistribución regresiva de la riqueza social lo que redunda en el crecimiento de la población pobre y la configuración de un patrón extremo de sobreconsumo- 
subconsumo. Así, los datos oficiales ${ }^{25}$ señalan que cerca de la mitad de los 85 millones de mexicanos viven en la pobreza y de ellos 17 a 20 millones en la pobreza extrema, o sea, no alcanzan a cubrir los mínimos de alimentación.

\section{PARA UN DIAGNÓSTICO DEL SECTOR SALUD}

El sector salud es uno de los ámbitos donde se expresa con más claridad la diferenciación de las políticas sociales en función de sus destinatários, ya que de entrada está segmentado en tres subsistemas -el paraestatal de seguridad social, el estatal público de "población abierta" y el privado- que abarcan grupos poblacionales distintos. Interesa, por ello, ver primero los problemas estructurales que esto conlleva para luego analizar las tendencias de transformación que la política sanitaria de los gobiernos de inspiración neoliberal está suscitando para tener un diagnóstico dinámico de los problemas en el campo de la salud.

\section{1) Los problemas estructurales del sector salud}

Durante los últimos veinte años ha sido un lugar común señalar la irracionalidad del sector salud mexicano por la proliferación de instituciones y programas que duplican algunas funciones y dejan sin atención a otras; desperdician recursos y, finalmente, no logran siquiera cubrir a toda la población con servicios. Ante 
esta situación se estableció en 1984 el Sistema Nacional de Salud (SNS). ${ }^{26}$ Sin embargo, analizando el SNS más de cerca resulta que fue más un cambio de nombre que de sustancia ya que no resolvió ninguno de los problemas de fondo desde la perpspectiva de una política que busca la universalidad e igualdad en los servicios de salud e, incluso, empeoró la situación en ciertos aspectos.

Dentro del SNS el subsistema de seguridad social mantiene esencialmente su estructura centralizada con la desconcentración de algunas funciones; se financia con las cuotas obrero-patronales y una aportación estatal decreciente en los últimos años; es de acceso selectivo condicionado al pago de cuotas; y ofrece servicios -gratuitos al momento de usarlos- preventivos, curativos de los tres niveles de atención y de rehabilitación. En 1989 declaró tener 44 millones de derechobahientes. ${ }^{27}$

El subsistema de servicios públicos de "población abierta" está en proceso de descentralización; se financia esencialmente con los impuestos, préstamos y cuotas pagadas al momento de usar los servicios; es, en principio, de acceso libre pero en los hechos lo usa la población excluida de los otros dos subsistemas; y ofrece servicios preventivos y curativos del primer nivel -cobrando cuotas de recuperación por el servicio- pero carece de un sistema integrado y regionalizado de referencia y contrareferencia de los tres niveles de atención. En 1989 declaró dar cobertura a 24 millones de personas y estimó la población sin cobertura en entre 10 y 15 millones. ${ }^{28}$

El subsistema privado, finalmente se financia con el pago por el servicio proporcionado; es de acceso abierto para quien pueda pagar; y ofrece servicios curativos de los tres niveles pagados por el usuario o su seguro privado al momento 
de usarse. Se desconoce qué proporción de la población acude a estos servicios pero medido en términos del costo monetario de los servicios produjo el $54.4 \%$ del PIB de servicios médicos en $1988 .^{29}$ Este dato no refleja el volumen de servicios que seguramente es menor.

Como se aprecia la formación del SNS, en vez de representar un paso hacia la futura integración de un Servicio Unico de Salud con acceso universal, significó la separación definitiva legal, financiera y funcional de los tres subsistemas. Esto a su vez se verifica en una diferenciación en la calidad y orientación de los servicios y se consolida como un elemento de desigualdad clasista ya que el acceso a uno u otro de los subsistemas está directamente vinculado a la ubicación social de los usuários. Asimismo, la preservación sin reservas de un sistema mixto público-privado reconoce al campo de los servicios de salud como un terreno legítimo de generación de ganancias.

Un segundo problema estructural del sector salud que afecta su funcionamiento y que se erige en un obstáculo para un proyecto democrático es su estructura vertical y autoritaria que se convierte en una de las bases del burocratismo. En esta estructura vertical la SSA es quien establece la política nacional de salud y constituye la instancia normativa con facultades de evaluación, supervisión y gestión financiera de los servicios, ${ }^{30}$ mientras que en las entidades federativas con sistemas descentralizados los gobiernos estatales asumen la responsabilidad en la materia de salubridad general pudiendo realizar convenios con los municipios para trasladarles funciones. 31 
El punto a resaltar es que los usuarios y trabajadores de las instituciones no tienen ninguna participación efectiva en la planeación, orientación y evaluación de los servicios. Es así, porque la "consulta popular" en el marco de la "planeación democrática" no significa poder de decisión. Asimismo, la relación institución-trabajadores es concebida como una relación estrictamente laboral ajena a las tareas de gestión institucional. Finalmente, la tan trillada participación comunitária tampoco significa poder de decisión y gestión sino tiene por finalidad "impulsar la colaboración organizada, informada, responsable y solidaria de la comunidad en su conjunto en materia de salud" ${ }^{32}$ dentro de los programas establecidos por la institución, lo que equivale a asumir parte del trabajo o los gastos de éstos.

El caso del IMSS pudiera parecer distinto ya que su estructura de gobierno es tripartita en los distintos niveles con la participación de representantes sindicales, patronales y del Estado. ${ }^{33}$ Sin embargo, el Ejecutivo Federal decide qué organizaciones sindicales y patronales nombrarán los representantes a la Asamblea, máximo órgano del Instituto, y al Consejo Técnico. ${ }^{34}$ Adicionalmente el Presidente de la República nombra el Director General que concentra prácticamente todo el poder de ejecución y, sólo, delega funciones en los organismos técnicos. Tiene, además poder de veto respecto a las decisiones del Consejo Técnico de estructura tripartita con doce miembros. La estructura tripartita se reproduce a nivel delegacional que es esencialmente operativo. Además hay que recordar que en el IMSS no está planteado un proceso de descentralización sino de desconcentración que preserva el poder centralizado. 
La injerencia que los usuarios pudieran tener por vía de los representantes sindicales en el IMSS, se ve restringida por el poder del Director General y por la antidemocracia imperante en el sistema corporativo mexicano. Sin embargo, cabe mencionar que la gestoría que los grandes sindicatos ejercen para defender los intereses de sus agremiados a veces se traduce en un mecanismo de poder y de corrección directo a nivel de los servicios. Por otra parte, los trabajadores y el sindicato de la institución no tienen ninguna injerencia en la gestión institucional, sea, en la planeación o evaluación de las actividades.

\section{2) La política sanitária y tendencias de transformación del SNS}

En el terreno de los servicios de salud los proyectos neoliberales, tal como se instrumentan en América Latina con una injerencia determinante de los organismos internacionales como el FMI y el BID, ${ }^{35}$ tienen como ejes centrales el recorte presupuestario, la focalización del gasto público en los grupos de extrema pobreza, la descentralización y la privatización. ${ }^{36}$ En México los tres primeros son políticas explícitas o fácilmente observables mientras que el propósito de privatizar no se ha declarado públicamente. Sin embargo a todas luces está en camino -tal como se analizará más adelante.

\section{a) Recorte presupuestario}

A pesar de las reiteradas declaraciones del carácter prioritário de la atención a la salud se dio un recorte presupuestario importante en este renglón durante 
los ochenta como se observa en el cuadro 1. Así al terminar la década, el presupuesto de todas las instituciones de salud aún era menor que en 1981 después de llegar a su punto más bajo en 1986 y 1987. Calculado per cápita la situación se agrava todavía más ya que el presupuesto del ISSSTE llega a tener una pérdida del 65\% en el peor año y del $44 \%$ en el periodo. Los datos correspondientes para el IMSS son $62 \%$ y $44 \%$ y para la SSA del $61 \%$ y $50 \%$. En el caso del IMSS-Coplamar los datos per cápita son los más indicativos dado que este programa pasó parcialmente a SSA con el proceso de descentralización. Asimismo, como se puede observar en el cuadro 2 el gasto en salud bajó al $4.7 \%$ al $2.7 \%$ del gasto público total. Por otra parte, el rezago del gasto en salud respecto a la recomendación de la OMS -5\% del PIB- es todavía más notable a fines de la década ya que bajó del 1.9 a $1.6 \%$.

Otro hecho importante a considerar es que, ante las restricciones presupuestarias, se privilegió el gasto corriente dejando rezagado el gasto de inversión. Así, globalmente en el sector salud la inversión cayó en $71 \%$ entre 1982 y 1983 manteniendo este nivel todavía en 1986. Esta tendencia fue aún más marcada en las instituciones de seguridad social ya que cayó en un $75 \%$ en 1983 sin ninguna recuperación para 1986. ${ }^{37}$ La sostenida restricción de la inversión no sólo impidió la expansión de los servicios sino que además provocó su deterioro paulatino.

La política de depresión salarial acelerada desempenhó um papel central en la disminución del presupuesto en dos sentidos. Así por una parte, afectó directamente los salarios. Por la otra, el recorte presupuestario sin disminución de la cobertura fue posible gracias a la depresión salarial de los trabajadores de la salud. De esta manera, el mayor peso de la crisis presupuestaria fue cargado por ellos. 
CUADRO 1: Evolución del Presupuesto de Salude, México, 1980-1989

\begin{tabular}{|c|c|c|c|c|c|c|c|c|c|c|c|c|}
\hline & \multicolumn{3}{|c|}{ SSA } & \multicolumn{3}{|c|}{ IMSS } & \multicolumn{3}{|c|}{ ISSST } & \multicolumn{3}{|c|}{ IMSS } \\
\hline & \multicolumn{3}{|c|}{ Pesos $1980^{2}$} & \multicolumn{3}{|c|}{ Pesos $1980^{2}$} & \multicolumn{3}{|c|}{ Pesos $1980^{2}$} & \multicolumn{3}{|c|}{ Pesos $1980^{2}$} \\
\hline \multirow[t]{2}{*}{ Año } & $\begin{array}{l}\text { Pesos } \\
\text { corrien- } \\
\text { tes }\end{array}$ & Total & $\begin{array}{l}\text { Per } \\
\text { capita }\end{array}$ & $\begin{array}{l}\text { Pesos } \\
\text { corrien- } \\
\text { tes }\end{array}$ & Total & $\begin{array}{l}\text { Per } \\
\text { capita }\end{array}$ & $\begin{array}{c}\text { Pesos } \\
\text { corrien } \\
\text { tes }\end{array}$ & s- Total & $\begin{array}{l}\text { Per } \\
\text { capita }\end{array}$ & $\begin{array}{l}\text { Pesos } \\
\text { corrien- } \\
\text { tes }\end{array}$ & Total & $\begin{array}{l}\text { Per } \\
\text { capita }\end{array}$ \\
\hline & 1 & 1 & 3 & 1 & 1 & 3 & 1 & 1 & 3 & 1 & 1 & 3 \\
\hline 1980 & 19.6 & 19.6 & n.d. & 47.3 & 47.3 & 1960 & 11.0 & 11.0 & 2251 & 1.71 & 1.7 & 692 \\
\hline 1981 & 28.5 & 22.1 & n.d. & 67.8 & 52.7 & 1957 & 16.2 & 12.6 & 2360 & 4.5 & 3.5 & 1648 \\
\hline 1982 & 45.3 & 17.7 & 1539 & 114.0 & 44.5 & 1657 & 25.1 & 9.8 & 1794 & 3.3 & 1.3 & 673 \\
\hline 1983 & 60.7 & 13.1 & 1050 & 186.2 & 40.2 & 1343 & 35.1 & 7.6 & 1343 & 11.5 & 2.5 & 1117 \\
\hline 1984 & 102.6 & 13.9 & 1032 & 295.1 & 40.1 & 1364 & $55 . C$ & 7.5 & 1227 & 10.1 & 1.4 & 565 \\
\hline 1985 & 169.6 & 14.1 & 912 & 429.1 & 35.6 & 1130 & 101.2 & 8.4 & 1301 & 22.7 & 1.9 & 685 \\
\hline 1986 & 300.8 & 12.4 & 782 & 654.8 & 26.4 & 850 & 168.4 & 6.8 & 976 & 35.4 & 1.4 & 879 \\
\hline 1987 & 737.4 & 11.5 & 604 & 1631.7 & 25.4 & 739 & 393.5 & 6.1. & 832 & 60.3 & 0.9 & 588 \\
\hline 1988 & 1527.8 & 15.7 & 719 & 3829.1 & 39.2 & 1120 & 793.7 & 8.1 & 1097 & 156.3 & 1.6 & 1039 \\
\hline 1989 & 1829.0 & 17.0 & 755 & 4307.0 & 40.0 & 1095 & $851 . C$ & 7.9 & 925 & 148.3 & 1.4 & 941 \\
\hline \multicolumn{3}{|c|}{ Pérdida máxima } & \multicolumn{3}{|c|}{ Pérdida máxima } & \multicolumn{3}{|c|}{ Pérdida máxima } & \multicolumn{3}{|c|}{ Pérdida máxima } & \\
\hline \multicolumn{3}{|c|}{ Período $47,9 \%$} & \multicolumn{3}{|c|}{ Período 51,8\% } & \multicolumn{3}{|c|}{ Período $51,6 \% \quad 64,7 \%$} & \multicolumn{3}{|c|}{ Período $74,3 \% \quad 65,7 \%$} & \\
\hline \multicolumn{2}{|l|}{ Pérdida } & & \multicolumn{3}{|l|}{ Pérdida } & \multicolumn{3}{|l|}{ Pérdida } & \multicolumn{3}{|l|}{ Pérdida } & \\
\hline \multicolumn{2}{|c|}{$1981-198923,1 \%$} & $50,1 \%$ & \multicolumn{3}{|c|}{$1981-198924,0 \% \quad 44,0 \%$} & \multicolumn{3}{|c|}{$1981-198937,3 \% 60,8 \%$} & \multicolumn{3}{|c|}{$1981-198960,0 \% \quad 42,9 \%$} & \\
\hline
\end{tabular}

Una segunda cuestión que resulta del recorte de los presupuestos es que el gasto per cápita de las distintas instituciones empieza a ser semejante -situación particularmente notable respecto al ISSSTE- igualándolo hacia abajo. Como se verá 
adelante esto es la base financiera de lo que se expresa como la generalización de la penuria en el sector público-paraestatal que constituye uno de los impulsos más importantes al proceso de privatización.

Visto el recorte presupuestario desde el ángulo de la redistribución del ingreso se observa su efecto regresivo en cuanto se transfieren mayores recursos estatales hacia el capital quitándolo del salario indirecto de los trabajadores. Este hecho aparece con claridad en el cuadro 2 donde se observa cómo el gasto de desarrollo social y de salud disminuyen el periodo, mientras que los recursos dedicados al servicio de la deuda -que no son otra cosa que ganancias especulativas del capital- crecen aceleradamente.

b) Focalización del gasto: de los pobres a los muy pobres

La política de focalizar el gasto público en los grupos más depauperados llega a su expresión más nítida con la fundación del Pronasol ya que este organismo tiene como objetivo explícito canalizar recursos para la solución de problemas sociales de los grupos de extrema pobreza. Sin embargo, esta política se viene instrumentando desde el sexenio pasado en el sector salud por medio de la fijación de prioridades institucionales y por cambios en los esquemas de financiamiento de las distintas instituciones. Así, las instituciones de salud tienen como prioridadd explícita atender el nivel básico, o sea, la atención primaria en salud; ${ }^{38}$ cuestión que se expresa en asignaciones presupuestarias con ritmos diferenciados de recorte y recuperación. ${ }^{39}$ Por otra parte, durante el sexenio pasado el gobierno federal bajó sus obligaciones financieras con el IMSS, dejando casi la totalidad del financiamiento de la institución 
a los patrones y trabajadores, recanalizando sus recursos a la Secretaría de Salud para atender a la población de menos recursos. ${ }^{40}$

Em abstracto la política de focalización del gasto puede parecer justa pero habría que juzgarla en el contexto socioeconómico mexicano y en función del paradigma de política social que implica. Así aunque nadie pueda negar el drama social que significa la extrema pobreza en la cual viven 17 millones de mexicanos, tampoco se puede ocultar que la pobreza es condición de cerca de la mitad de la población

Cuadro 2: Evolución del \% del gasto público para servicio de la deuda, desarrollo social y salud, México 1980 a 1989

\% Gasto Público Total

\begin{tabular}{lccc}
\hline & Servicio deuda & Desarrollo Social & Gasto Salud \\
\hline 1980 & 30.0 & 17.3 & 4.7 \\
1981 & 25.1 & 16.8 & 4.4 \\
1982 & 41.1 & 14.8 & 3.8 \\
1983 & 42.4 & 12.2 & 3.5 \\
1984 & 40.0 & 12.4 & 3.5 \\
1985 & 40.7 & 13.3 & 3.6 \\
1986 & 53.0 & 10.9 & 2.9 \\
1987 & 57.9 & 9.8 & 2.7 \\
1988 & 60.0 & 9.7 & 2.9 \\
1989 & 61.0 & 10.5 & 2.7 \\
\hline
\end{tabular}

Fuente : Primer Informe de Gobierno, Poder Ejecutivo Federal, 1989 
y que la absoluta mayoría de los trabajadores está experimentando un grave deterioro de sus condiciones de vida. Dada esta situación concreta la focalización del gasto en los grupos más pobres, antes que una política de justicia social, aparece como un artífice ideológico para justificar que el Estado desatienda su obligación constitucional de garantizar los derechos sociales de todos los mexicanos.

Por otra parte, el modelo de política social que se perfila con este planteamiento se acerca mucho más a la política de un Estado asistencialista que la de un Estado de bienestar tanto por su alto grado de selectividad basada en criterios de comprobación de la pobreza como por los reducidos servicios proporcionados que no rebasan la atención primaria selectiva. ${ }^{41}$ Además está conceptualmente ligado a la privatización ya que reserva sus recursos para los más pobres exigiendo "que pague quien pueda", sea dentro de los servicios públicos con las cuotas de recuperación, sea comprando el servicio en el mercado. En términos redistributivos no significa una redistribución global del ingreso social sino que se basa en la redistribución del menguado gasto social hacia los más pobres a costa de otros sectores depauperados como ilustra claramente el caso del financiamento del IMSS.

c) Descentralización: verticalismo e incompetencia técnica

El tercer eje de los proyectos neoliberales, la descentralización, se ha impulsado en el sector salud desde 1984 y sigue siendo un propósito declarado del Plan nacional de Desarrollo. ${ }^{42}$ De nuevo es un planteamiento que en abstracto puede resultar atractivo frente al agobiante centralismo mexicano. Sin embargo, las características de esta descentralización y sus efectos muestran limitaciones serias. 
Así, fue decretada unilateralmente por el Ejecutivo para el subsistema de población abierta $^{43}$ y su instrumentación ha resultado vertical y antidemocrática. No podía ser de otro modo ya que no contempló mecanismos de redistribución real de poder de decisión sobre los programas entre los involucrados en los servicios, a saber, las instancias locales de gobierno, los usuarios y los trabajadores. ${ }^{44}$ Aun en el caso de que esto se hubiera dado, resultaría además una formalidad en el contexto del sistema corporativo mexicano donde los mecanismos democráticos no operan en la absoluta mayoría de los municipios y organizaciones de masas impidiendo una representación auténtica de los ciudadanos y los trabajadores.

Por otra parte la premura del proceso no permitió una adecuada preparación técnica, lo que redundo en ocasiones en el virtual colapso de los servicios, particularmente en lo relacionado con la integración de los programas verticales y de los servicios del IMSS-Coplamar a los sistemas estatales. ${ }^{45}$ Además, los recursos transferidos a los niveles estatal y municipal antes que incrementar la eficiencia institucional tendieron a ser utilizados a la discreción de grupos locales de poder. Finalmente, la descentralización precipitó pugnas entre grupos burocráticos que trataron de defender o promover sus intereses particulares. Ante estas realidades la descentralización no llegó a instrumentarse en mas que doce estados y parece estar suspendida ya que sus costos en términos de mal funcionamiento institucional han sido muy altos. Sin embargo, dado que la descentralización en su variante neoliberal es un medio de desestatización que permite instrumentar nuevos esquemas de producción de servicios y de financiamiento es probable que continuará una vez que se hayan hecho los ajustes institucionales necesarios. 
d) Nuevos y viejos problemas

Entre los problemas que han sido provocados o profundizados con la política sanitaria en curso se observa, en primer lugar, una creciente desigualdad entre los distintos grupos y clases sociales en términos del acceso real a los servicios y en el tipo y calidad de los servicios disponibles para cada uno de ellos. En el fondo de este problema está el abandono de una política de seguridad social cuyo objetivo es construir tendencialmente una institución de salud única con acesso universal. La actual política, por el contrario, da por resultado la separación definitiva y desarrollos divergentes de los tres subsistemas de salud existentes en México.

Las limitaciones de acceso a y calidad de los servicios de la población pobre no-asegurada empiezan con los 10 millones de mexicanos al margen de cualquier servicio. ${ }^{46}$ Luego, por las restricciones presupuestarias -dispone del $27 \%$ del gasto público en salud- los servicios públicos de población abierta sólo garantiza la atención primaria selectiva sin poder proporcionar servicios del segundo y tercer nivel a todos que lo requieren. A ello se añade otro elemento que dificulta el acceso a los servicios de salud como es la introducción o el aumento de las "cuotas de recuperación" cobradas al utilizarlos ya que condicionan el acceso a la capacidad de pago de los usuarios. Esto tiene peso particularmente al segundo y tercer nivel donde las cuotas pueden representar cantidades muy por encima del salario mínimo mensual.

Por su parte los institutos de seguridad social disponen del $63 \%$ del gasto público en salud para atender a sus derechohabientes con los tres niveles de atención. Sin embargo, la demanda de sus servicios aumentó sustancialmente por la expansión 
formal del número de derechohabientes -la cobertura de la seguridad social aumentó en $35 \%$ de 1982 a $1989-47$ sin un incremento correspondiente de recursos con el resultado de que el presupuesto por derechohabiente bajó en un 44\% en el IMSS y un $61 \%$ en el ISSSTE (ver cuadro 1). A este incremento de demanda se suma otro, resultado de la exclusión de sectores de asegurados de los servicios privado por su alto costo.

El desequilibrio entre demanda y recursos ha obligado a las instituciones de seguridad social a profundizar los obstáculos burocráticos de acceso a sus servicios. De esta manera, a partir de 1986, año en el cual empieza el crecimiento rápido de cobertura, todos los indicadores de servicios prestados en relación al número de derechohabientes, como consultas generales y de especialidad, hospitalizaciones, partos, etc., decaen sistematicamente. ${ }^{48}$ Es decir, aunque más mexicanos formalmente son derechohabientes de estas instituciones hay crecientes dificultades para acceder a sus servicios.

El acceso a los servicios privados, finalmente depende directamente de la capacidad económica, y a todas luces se ha visto restringido para los individuos por su altísimo costo y la pérdida de poder de compra de amplios sectores medios asalariados. Por otra parte, los que tienen la capacidad económica pueden acceder a los servicios de los tres niveles sin restricciones disgnósticas y de tratamiento.

Un segundo problema provocado por la política neoliberal hacia las instituciones públicas de salud es el surgimiento de un conflicto laboral serio, ya que esta política busca resolver las contradicciones originadas por la restricción de 
recursos cargándolas sobre los trabajadores de las instituciones. Así, éstos han sufrido un marcado deterioro salarial a partir de $1983^{49}$ que en muchas ocasiones los obliga a tener dos empleos. Acompaña, además, a este fenómeno una creciente diferenciación salarial entre el sector público y el privado; p.e. un médico gana en un día de práctica privada su salario mensual institucional. Esta situación tiende a drenar al sector público de su personal más calificado y canalizarlo al privado.

Por otro lado, los procesos de racionalización basados en planteamientos de la organización científica del trabajo, que concibe a la experiencia e iniciativa de los trabajadores no como una potencialidad positiva sino algo que debe ser regulado y suprimido, han significado el creciente control vertical sobre el trabajo y su normatización estricta. El efecto directo de ello es un proceso de descalificación del trabajo institucional incluso el de los profesionistas. Esta situación es otra de las razones que propicia el abandono del trabajo en la institución publica y una recomposición del perfil de calificación en ella acompañada de una tendencia a la feminización como suele suceder con los trabajos mal pagados y descalificados.

Al proceso de descalificación del trabajo se añade, además, el deterioro de las condiciones de trabajo como el resultado de la política de incrementar la cobertura de los servicios sin el incremento correspondiente en los recursos necesarios para realizar el trabajo. $Y$ como si fuera poco los trabajadores de las instituciones son los que tienen que enfrentar cotidianamente la presión de los ususarios y las quejas de las deficiencias del servicio sin contar con las condiciones materiales y de decisión para poderlos mejorar. 
Se puede suponer que el descontento de los trabajadores de las instituciones se agrava todavía más porque el deterioro salarial y de las condiciones de trabajo se ha dado como imposición unilateral y al margen de cualquier negociación efectiva. Apoya esta suposición el surgimiento reiterado de movimientos sindicales democráticos en las distintas instituciones de salud durante los últimos años.

El recorte presupuestario, el autoritarismo, la descalificación del trabajo y las malas condiciones de trabajo han provocado un marcado deterioro de los servicios de las institucones de salud que ha contribuido a desprestigiarlas ante la sociedad. Lentamente han transitado de ser instituciones legitimadoras del Estado a convertirse en espacios de conflicto social donde chocan demandantes de servicios que los consiguen con dificultad y productores de servicios sin condiciones para prestarlos adecuadamente. El conflicto y desprestigio se dan con más intensidad en las instituciones cuyo proceso de deterioro ha sido más marcado como el ISSSTE o que son usadas por sectores organizados o con mayor capacidad reivindicativa como son las de la seguridad social.

\section{3) Hacia la privatización de los servicios ?}

El creciente deterioro y desprestigio de las instituciones públicas, en sus modalidades estatal y paraestatal, constituye el contexto, por así decirlo, ideológico del proceso de privatización de los servicios de salud en México ya que contribuye a hacerlo socialmente aceptable. Sin embargo, también tiene una sólida base material 
por el creciente peso de la medicina privada en la última década y por los márgenes de ganancias que reporta.

En el cuadro 3 se puede observar la participación de los sectores público y privado en el producto interno bruto de servicios médicos (PIBSM) y su desarrollo durante la década. Una primera cuestión que llama la atención es que aun incluyendo a los servicios privados el PIB en salud está lejos del 5\% del PIB global recomendado por la OMS. Sin embargo, los hechos más importantes que se desprenden del cuadro son que al sector privado le corresponde cerca de la mitad del PIBSM y que su peso es creciente a partir de 1983, año en el cual contribuye con el $56.7 \%$ llegando a un máximo en 1985 con el $60.2 \%$ para estabilizarse en el $54 \%$ en 1987 y 1988 . Esto no quiere decir que el sector privado produce, en volumen, la mitad de los servicios sino más bien refleja sus altos precios; hecho que se demuestra en que los precios de los servicios privados crecieron 930 veces entre 1980 y 1989 en comparación con 470 veces en el sector público (ver cuadro 5).

Esto nos lleva a la segunda cuestión relacionada con el proceso de privatización que es el nivel de rentabilidad de este sector. El cuadro 4 pretende ilustrar el problema mostrando la evolución del exedente bruto de operación, o sea, el excedente después del pago de salarios e insumos intermedios. Este excedente fue el $63 \%$ de la producción bruta en 1980 y creció a $70 \%$ en $1988 .^{51}$ En el cuadro se puede observar que el excedente del sector privado es muy alto llegando a 5 billones de pesos en 1988. Como punto de comparación se puede mencionar que este excedente es el doble que el de la rama de televisión, radio y cine; 2.5 veces mayor que los de la industria farmacéutica y de automóviles; casi igual al de la industria básica 
del hierro y acero; $20 \%$ mayor que la rama de electricidad y sólo $25 \%$ menor que la rama de las instituciones de crédito y seguros. ${ }^{52} \mathrm{O}$ sea, la producción privada de servicios médicos es una de las ramas más rentables de la economia mexicana. Por otra parte, el excedente crece casi un 60\% entre 1980 y 1985 a precios constantes y en 1988 está un $22 \%$ más alto que en 1980 . O sea, a pesar del crecimiento lento de la economía la medicina privada incrementa el nivel de su excedente.

Sin embargo, se puede argumentar que un mayor crecimiento de los servicios médicos privados enfrenta como obstáculo las restricciones del mercado y que sólo podrían expandirse encontrando mecanismos para crear un nuevo mercado garantizado y estable. En las condiciones actuales de empobrecimiento de la población esto sólo sería posible por medio de los seguros médicos, particularmente, en su forma colectiva. Si es así, la clientela buscada por las instituciones privadas tendría que ser los trabajadores organizados sindicalmente con ingresos fijos por encima del salario mínimo, o sea, los que hoy son la parte más importante de los asegurados de los institutos de seguridad social.

Una serie de hechos apoyan la posibilidad de que se constituya este nuevo mercado. Así, la Ley del Seguro Social ${ }^{54}$ establece la opción de contratar servicios médicos para los trabajadores fuera del IMSS siempre y cuando la patronal y el sindicato lo acuerden. En este caso hay, además, reversión de la cuota correspondiente. Vista esta opción en el contexto del deterioro y deslegitimización de los servicios médicos de la seguridad social se aprecia que puede resultar tentadora para los sindicatos. A favor de que el proceso de privatización de la prestación de servicios médicos a los trabajadores sindicalizados está en marcha habla, también, el 
hecho de que el esquema de seguros colectivos privados ya está funcionando entre los trabajadores bancarios y del Metro, y en muchas empresas propiedad de los empresarios más agresivamente antiestatistas. Y como si fuera poco a últimas fechas se ha otorgado un seguro médico colectivo de Gastos Médicos Mayores a grupos como los universitarios sin que éstos lo hayan solicitado. 55

Cuadro 3: Evolución del Producto Interno Bruto de los servicios México 1980-1988

\begin{tabular}{|c|c|c|c|c|c|c|c|c|c|}
\hline $\begin{array}{l}\text { Servicios } \\
\text { Médicos }\end{array}$ & 1980 & 1981 & 1982 & 1983 & 1984 & 1985 & 1986 & 1987 & 1988 \\
\hline PIB* & 132,753 & 195,221 & 343,669 & 565,466 & 916,128 & $1.454,541$ & $2.344,907$ & $5.362,011$ & $10.603,000$ \\
\hline $\begin{array}{c}\% \text { del PIB } \\
\text { total }\end{array}$ & 2.9 & 3.1 & 3.5 & 3.1 & 3.1 & 3.0 & 2.9 & 2.7 & 2.7 \\
\hline $\begin{array}{l}\text { Sector } \\
\text { privado * }\end{array}$ & 62,232 & 93,191 & 164,281 & 320,909 & 535,992 & 876,259 & $1.372,575$ & $2.919,514$ & $5.800,000$ \\
\hline $\begin{array}{c}\% \text { del PIB } \\
\text { total }\end{array}$ & 1.3 & 1.5 & 1.6 & 1.7 & 1.8 & 1.8 & 1.7 & 1.5 & 1.4 \\
\hline $\begin{array}{l}\text { \% del PIB } \\
\text { serv. } \\
\text { méd. }\end{array}$ & 46.8 & 47.7 & 47.8 & 56.7 & 58.5 & 60.2 & 58.5 & 54.5 & 54.7 \\
\hline $\begin{array}{l}\text { Sector } \\
\text { público* }\end{array}$ & 70,521 & 102,030 & 179,388 & 244,557 & 380,136 & 588,282 & 972,332 & $2.442,497$ & $4.803,000$ \\
\hline $\begin{array}{c}\% \text { del PIB } \\
\text { total }\end{array}$ & 1.5 & 1.6 & 1.8 & 1.3 & 1.2 & 1.2 & 1.2 & 1.2 & 1.2 \\
\hline $\begin{array}{l}\text { \% del PIB } \\
\text { serv. } \\
\text { méd. }\end{array}$ & 53.1 & 52.2 & 52.5 & 43.2 & 41.4 & 39.7 & 41,4 & 45.5 & 45.3 \\
\hline PIB total & $4.470,077$ & $6.117,632$ & $9.797,791$ & $17.878,720$ & 9.471 .575 & $47.391,702$ & $79.353,450$ & $193.612,286$ & 392.791 .000 \\
\hline
\end{tabular}

Fuente: Sistema de Cuentas Nacionales de México. 1980-1988, Tomo I cuadro 1 y Tomo III cuadro 191.

* Milones de pesos. 
La última cuestión con relevancia para este problema es la nueva reglamentación sobre la participación del capital extranjero en el mercado de seguros aprobada en $1989 .{ }^{56} \mathrm{~A}$ ello se añade el anuncio del acuerdo de libre comercio con los EUA que abarcará también los servicios. La importancia de ello radica en que las compañías aseguradoras y el complejo médico-industrial norteamericano tienen amplia experiencia y sólidas estructuras que les facilitarían expandir sus actividades en México. O sea, allanados los obstáculos a la expansión del mercado, los servicios médicos privados pudieran transnacionalizarse rápidamente.

Cuadro 4: Evolución del excedente bruto de producción* en el sector salud, México, 1980-1988

\begin{tabular}{lccc}
\hline Año & Total & \multicolumn{2}{c}{ Del sector privado } \\
& Pesos corrientes & Pesos corrientes & Pesos de 1980 \\
\hline 1980 & 51,208 & $50,695.9$ & $50,695.9$ \\
1981 & 76,783 & $76,015.2$ & $60,329.5$ \\
1982 & 139,710 & $138,312.9$ & $68,201.6$ \\
1983 & 280,405 & $277,601.0$ & $78,774.4$ \\
1984 & 472,159 & $467,437.4$ & $76,080.3$ \\
1985 & 773,358 & $765,624.4$ & $79,512.3$ \\
1986 & $1,208,687$ & $1,196,600.1$ & 71.302 .6 \\
1987 & $2,564,971$ & $2,539,321.2$ & $63,187.6$ \\
1988 & $5,090,538$ & $5,039,632.6$ & $61,535.5$ \\
\hline
\end{tabular}

Fuente: Elaboración propia. Ver referencia 53.

* Millones de pesos. 
Estos elementos permiten constatar que el proceso de privatización en el sector salud no implica la venta de las instituciones de salud como ha ocurrido con otras empresas públicas. El rasgo básico del proceso privatizador, entonces, es el crecimiento paralelo de la iniciativa privada y su expansión en sectores anteriomente atendidos por el Estado. Junto a ello se puede dar la subrogación de algunos servicios pero sin que llegue a ser la forma dominante como es, p.e., en Brasil. ${ }^{57}$ El resultado de un proceso con estas características sería un debilitamiento profundo de los institutos de seguridad social, ya que perderían su papel motor de la expansión de los benefícios de la seguridad social a toda la población para redirigirse a proporcionar servicios a los sectores de trabajadores más pobres y a administrar programas de caridad pública en el marco de una política asistencialista.

No obstante, frente a la tendencia privatizadora se presenta una contratendencia importante de defensa de la institución pública. Así, si bien las carencias y dificultades cotidianas sufridas por cada quien tienden a ser interpretadas como inherentes a las instituciones y justificadoras de su privatización, hay una creciente conciencia colectiva de que el problema no está necesariamente en la institución pública como tal sino en la política que la orienta. Además, se percibe que la constitución de un sector privado importante le da fuerza para obstaculizar y detener el crecimiento del sector público y que el esquema de producción privada de servicios incrementa su costo y crea déficits de cobertura. Por ello, tanto en las luchas sindicales de los últimos años -p.e. del IMSS- como en las de los "usuarios" -p.e. el Foro del ISSSTE- se ha planteado con insistencia la defensa, recuperación y transformación democrática de las instituciones públicas. Cuando ello ocurre el enfrentamiento entre 
trabajadores y usuarios se convierte en una alianza estratégica alrededor de objetivos comunes que constituyen el embrión de un proyecto de transformación alternativo que los partidos de oposición han retomado y empezado a elaborar. ${ }^{58}$

\section{PARA UNA POLÍTICA DE SALUD DEMOCRÁTICA Y POPULAR}

El análisis de la situación y tendencias de desarrollo de los servicios de salud revela la necesidad de proponer una reorientación global de la política sanitaria que recupere el mandato constitucional del derecho a la protección de la salud y una concepción social de la salud colectiva, y en este marco, delinear los principios estratégicos para solucionar los problemas detectados. Se trata pues de hacer una propuesta que permite revertir la política social neoliberal y plantear medidas que contemplen políticas generales con impacto en la salud; que prioricen el fortalecimiento y expansión de las instituciones públicas hasta alcanzar la universalidad y la igualdad; que impulsen su transformación democrática; y que profundicen su papel redistributivo de la riqueza social hacia las clases trabajadoras.

En el debate sobre las posibles salidas a la crisis se ha insistido, con razón, en la necesidad de que las propuestas sean factibles. Sin embargo, habría que insistir en que esta factibilidad tiene que ser pensada tanto en términos económicos como políticos. Este punto de partida debe ser contemplado en el proyecto alternativo para que su construcción se convierta en un elemento que propicie un cambio de 
correlación de fuerza favorable al bloque democrático-popular; cuestión que es a la vez uno de sus objetivos y condición de su éxito. Esto resulta particularmente importante en la situación de México, ya que so pretexto de la "pérdida de confianza" la gran burguesía ha saboteado -con fuga de capital y huelga de inversiónproyectos económicos que en sí mismos no necesariamente eran inviables.

1) Punto de partida: elementos de política general

Toda política de salud descansa sobre una concepción, implícita o explícita, de cómo se produce el proceso salud-enfermedad. Un proyecto de salud alternativo democrático-popular tiene que basarse en una concepción que da cuenta de los determinantes sociales del proceso salud-enfermedad de las colectividades humanas como lo hace la medicina social latinoamericana. Esta concepción ubica a los principales determinantes de las formas de enfermar y morir en las condiciones resultantes de la inserción específica de cada una de las colectividades humanas en la producción social. ${ }^{59}$ De allí sigue la necesidad de destacar en la propuesta alternativa no sólo acciones referidas al sector salud sino también medidas de política general. Esto es, si los problemas de salud son una expresión específica de las condiciones de trabajo y vida de los distintos grupos sociales, su solución no puede separarse de la transformación y el creciente control democrático sobre estas condiciones. 
Com base en su determinación social se puede agrupar la principal problemática de salud hoy presente en México en dos grandes conjuntos: aquel determinando por las características del consumo y aquel relacionado con las características de los procesos de trabajo. De esta manera, cualquier proyecto en salud que pretenda resolver de raíz los problemas del primer conjunto requiere contemplar cuestiones como las políticas de salario y empleo; de vivienda y saneamiento básico; de nutrición y agraria; y de desarrollo urbano y ecologia. Por otra parte, para atacar los problemas del segundo conjunto es obligado contemplarlos en la política laboral e industrial.

Casi todos los programas de salud reconocen esta situación y pretenden resolverla con el planteamiento de la coordinación intersectorial. Sin embargo, en la práctica no se analiza sistematicamente cuál pudiera ser el impacto de las distintas políticas en la salud colectiva, sea porque está considerada, de hecho, como una prioridad secundaria o porque se tiene una idea mecámica de la relación entre crecimiento económico y salud. ${ }^{60}$ Por ello, es necesario resaltar el problema introduciendo una especie de "contabilidad sanitaria", de modo que toda planeación económica y social contemple el problema de salud de forma sistemática. Es factible hacerlo, ya que el reconocimiento básico requerido existe e, incluso, ha servido de base para legislación concreta. ${ }^{61}$ Además, si se asumiera como práctica sistemática daría un impulso a la investigación con esta orientación. La "regla de oro" sería que no se justifica ninguna racionalidad productiva que tenga altos costos humanos de desgaste, enfermedad y muerte, ni que se constituya en una amenaza a la salud de grandes grupos de población, como el uso de energía nuclear. En esta perspectiva 
resulta particularmente importante analizar tres aspectos de las condiciones de trabajo: la tecnología empleada, las sustancias químicas utilizadas y la organización y división del trabajo, ya que son los determinantes principales de las nuevas epidemias -las enfermedades isquémicas del corazón y el cáncer- que hoy afectan a la población productiva del país. $^{62}$

La "contabilidad sanitaria" adquiere particular importancia en el contexto de la reestructuración productiva porque las nuevas tecnologías, la organización del trabajo y la relación salarial impuestas conllevan problemas importantes para la salud. ${ }^{63}$ Puede argumentarse que la proposición de realizar una contabilidad sanitaria es inviable ya que disminuiría la competitividad de los productos mexicanos en el mercado internacional. Sin embargo, es socialmente inaceptable basar el crecimiento económico en el desgaste prematuro de algunos trabajadores y el empobrecimiento acelerado de otros y, por ello, es una exigencia democrática mínima proporcionar la suficiente información para que se pueda analizar las implicaciones económicas y sociales de distintas opciones productivas. Además, este tipo de análisis se ha mostrado viable cuando existe voluntad para realizar y fuerza política para instrumentar sus resultados. 64

Por otra parte, la concepción de los determinantes y la importancia de los distintos problemas de salud también tienen implicaciones para la orientación general de los servicios de salud. Así, incrementar el impacto de la acción institucional en la salud colectiva significa enfatizar la prevención y promoción de la salud y el primer nivel con la atención máxima e integral a problemas claves estableciendo programas a nivel municipal y comunitario con la participación de organismos democráticos y 
sindicatos en su planeación y gestión. Sin embargo, el pleno cumplimiento del derecho a la protección de la salud no admite restringir el acceso al primer nivel de atención sino que requiere del crecimiento armónico de los tres niveles de atención y la construcción de un sistema de referencia y contrareferencia.

2) Hacia el Servicio Unico de Salud universal e igualitario

La reorientación global de la política de salud en lo referente al propio sector descansaría sobre el princípio básico de la obligación del Estado de garantizar el derecho a la protección a la salud, o sea, plantea su cumplimiento como función pública. El punto de llegada, o si se quiere, horizonte utópico, planteado en la propuesta alternativa de política sanitaria es un Servicio Unico de Salud, universal e igualitario. En las condiciones actuales de México no se puede instaurar de inmediato un sistema público e igualitario de salud con acceso universal y gratuito ya que un cambio repentino en este sentido seguramente causaría situaciones caóticas en los servicios. Sin embargo, no hay impedimento para contraer el compromiso explícito de lograrlo en un determinado lapso y tomar medidas específicas encaminadas a allanar el camino para llegar a ello.

Así, para arribar a un Servicio de Salud Unico gratuito, con cobertura y acceso universal, habría que emprender un proceso de integración de los subsistemas público y de seguridad social. Los primeros pasos serian, entonces, el establecimiento de la Secretaría de Seguridad Social y Salud y de una institución única de seguridad 
social. Es, además, preciso ir uniformando la legislación, la normatividad, orientación y contenido de los servicios, y las formas de financiamiento de las instituciones. El principal obstáculo a vencer es evitar que la integración de las instituciones resulte en un deterioro todavía mayor de los servicios por una repentina sobrecarga de demanda y falta de preparación administrativa y técnica para resolver la problemática sanitaria, ya que ésto ha sido un elemento importante de deslegitimación de los procesos de reforma sanitaria en otros países. ${ }^{65}$

Es decir, pensado en términos de construcción de la fuerza política necesaria para hacer realidad la propuesta de servicios de salud universales e igualitarios es importante no sólo considerar su potencialidad de unificar un gran bloque social a favor sino también instrumentarlo de tal modo que no aparezca como una desventaja para los actuales derechohabientes de los institutos de seguridad social y un avance dudoso para los no asegurados por la poca capacidad de los servicios de resolver sus problemas.

3) Disminuir la importancia del sector privado

El fortalecimiento del sector público requiere de una política expresa respecto al sector privado de salud ya que no son sistemas independientes sino que se condicionan mutuamente. Para esclarecer este hecho es necesario revisar los principales argumentos contra la producción privada de servicios y las implicaciones del proceso de privatización para los servicios públicos. 
El primer argumento es que la existencia del sector privado se erige como un obstáculo al acceso universal a un servicio de salud igualitario. Esto ocurre principalmente por dos razones. Una es que en cuanto la medicina privada opera con criterios de rentabilidad no está en su lógica proporcionar servicios a toda la población sino sólo a aquellos que los pueden pagar, sea directamente o por medio de un sistema de seguros médicos. La limitación que ello significa en un país como México es obvia con la mitad de la población en condiciones de pobreza. La única forma de hacer extensivos los servicios médicos producidos por el sector privado sería, entonces, que fueran pagados por el Estado mediante un seguro médico universal y no directamente por los usuarios. Este planteamiento se acerca a la situación imperante en el Brasil hasta el inicio del proceso de reforma sanitaria. ${ }^{66}$ Este sistema mostro tener todas las desventajas y ninguna ventaja ya que resultó ser de elevados costos; mal distribuido territorialmente; terreno propicio del fraude y la corrupción; de calidad desigual y de dudoso profesionalismo; un mecanismo de explotación del trabajo profesional, etcétera.

La otra razón por la cual el sector privado significa un obstáculo a la universalización de los servicios de salud es que, si crece en importancia, adquiere la fuerza política necesaria para impedir la expansión del sector público que considera una amenaza a sus intereses particulares. Los EUA es el caso clásico que ilustra este hecho. Así, en aquel país no se ha logrado implantar siquiera un seguro nacional de salud y menos un servicio nacional de salud por la tenaz resistencia del complejo médico-industrial ${ }^{67}$ a pesar de haber estado en la agenda política de las fuerzas del centro, centro-izquierda y izquierda desde hace cincuenta años. El resultado inmediato 
de ello es un déficit importante de cobertura estable que es del $16 \%$ de la población, o unos 38 millones de personas. ${ }^{68}$ o sea, uno de los principales problemas de la constitución de un amplio sector privado con fuerza es que detiene el sector público $y$, con ello, obstaculiza la solución de la problemática sanitaria de sectores importantes de la población.

Por otra parte, el esquema de producción privada de servicios incrementa su costo para la nación y los individuos. De nuevo los EUA ilustra este hecho ya que gasta en salud el 11\% del PIB, que es más que cualquier otro país, a pesar de no dar cobertura a toda la población. ${ }^{69}$ Los resultados de un estudio de costo beneficio de este país son reveladores porque demuestran que la implantación de un Servicio Nacional de Salud con cobertura y acceso universal salvaría entre 47 mil y 106 mil vidas al año y disminuiría el gasto total de salud en 2.4\% (10.2 mil millones de dólares) principalmente por medio de la eliminación de los gastos administrativos erogados para impedir el acceso de los no asegurados a los servicios. ${ }^{70}$

En el caso de México el impacto de un crecimiento de los servicios privados probablemente sería todavía más dramático para la economía nacional si se observa el desarrollo de precios de los sectores privado y público en la última década (cuadro 5).

El cuadro demuestra, primero, que el crecimiento de los precios de los servicios médicos fue más lento que los del PIB total, ya que entre 1980 y 1988 el índice de precios implícitos del PIB total creció 81.9 veces y el del PIB de servicios médicos 64.3 veces. Sin embargo, el crecimiento más lento del índice de precios de los servicios médicos se debe exclusivamente a los precios del sector público ya que crecen a 
mitad del ritmo de los del PIB total. El índice de precios del sector privado tiene un comportamiento inverso ya que se mantiene por encima del índice del PIB total en todo el periodo, o sea, incluso sobrecompensa el ritmo promedio de inflación. Esto significa que el sector privado cobra un sobreprecio por los servicios en relación al sector público que llega a ser del $98.5 \%$ en 1988.

Cuadro 5: Evolución de los índices de precios implícitos del PIB total y de servicios médicos, México 1980-1988

\begin{tabular}{|c|c|c|c|c|c|}
\hline & & INDICE & RECIOS & & \\
\hline & $\begin{array}{l}\text { Implícito de } \\
\text { PIB Total }\end{array}$ & & $\begin{array}{l}\text { lícito de } \\
\text { icios Méc }\end{array}$ & & $\begin{array}{l}\text { Sobreprecio } \\
\text { servicios }\end{array}$ \\
\hline & & Global & Público & Privado & Privados \\
\hline & 1 & 2 & 3 & 4 & $4-3 / 3 \times 100$ \\
\hline 1980 & 100 & 100 & 100 & 100 & 0 \\
\hline 1981 & 126 & 133.5 & 130.2 & 137.2 & 5.3 \\
\hline 1982 & 202.8 & 221.7 & 211.3 & 234.3 & 8.8 \\
\hline 1983 & 386.1 & 252.4 & 279.2 & 440.0 & 57.5 \\
\hline 1984 & 614.4 & 555.2 & 426.1 & 707.1 & 65.9 \\
\hline 1985 & 962.9 & 871.7 & 638.6 & $1,148.5$ & 79.8 \\
\hline 1986 & $1,678.2$ & $1,438.4$ & $1,032.0$ & 1,994.2 & 93.2 \\
\hline 1987 & $4,018.7$ & $3,278.5$ & $2,491.7$ & $4,455.2$ & 78.8 \\
\hline 1988 & $8,189.8$ & $6,431.3$ & $4,684.5$ & $9,302.2$ & 98.5 \\
\hline
\end{tabular}

Fuente: Sistema de Cuentas Nacionais de México 1980-1988, t. III, cuadros 353 y 353.2. 
El significado de estos datos es que si el Estado decidiera subrogar mañana al sector privado todos los servicios de salud que presta le costaría a la nación el doble de lo que hoy paga. Ese cálculo, además se basa en la suposición de que los precios público y privado fueron iguales en 1980; suposición seguramente incorrecta ya que hay elementos para decir que los precios privados ya eran más altos. Es además conveniente señalar que los servicios del sector privado no son más caros porque tienen gastos más altos -bajaron los gastos en consumo intermedio y salarios-sino porque aumentó el superávit bruto de operación y las ganancias. ${ }^{71}$

Un tercer argumento contra el sector privado de salud es que su lógica selectiva y de rentabilidad imprime una orientación curativa y no preventiva a los servicios. Además sus servicios tienden a ser sobretecnologizados y apoyarse en criterios deintervención basados más en la rentabilidad económica que en consideraciones terapéuticas médicas lo que se expresa en el empleo de métodos diagnósticos y cirurgías de dudosa utilidad que incrementa las iatrogenias. ${ }^{72}$

Las implicaciones políticas, sociales y económicas del crecimiento dela medicina privada explican por qué las fuerzas democrático-populares necesitan impedir el proceso de privatización que hoy está en marcha ya que significaría una reversión real de las instituciones del Estado de bienestar con consecuencias inmediatas y a largo plazo. Pero aparte de frenar en lo inmediato la privatización la propuesta alternativa debe plantear políticas para el largo plazo respecto al sector privado que tienden a restringirlo y asentar que no es socialmente deseable que sea un terreno de generación de ganancias y menos de ganancias extraordinarias. 
Es por ello necesario instrumentar mecanismos estrictos de regulación de la producción privada de servicios estableciendo normas de calidad y supervisar su cumplimiento por medio de auditorías médicas. Es además un sector donde se justifica el control de precios tanto por razones éticas como por el comportamiento que han tenido en el último periodo. Por otra parte, habría que contemplar mecanismos específicos de control sobre la industria farmacéutica y de equipo médico para reducir su alto costo e influencia sobre el modelo de atención.

4) Democratización de la acción pública

No es suficiente con tan sólo reafirmar el compromiso con la producción pública de servicios sin simultáneamente atender el problema real que nutre el discurso antiestatista- privatizador, a saber, el descrédito de una acción estatal caracterizada por el ejercicio autoritario y discrecional de poder, el favoritismo, el clientelismo, el burocratismo, la ineficiencia y la corrupción. El equívoco del discurso privatizador es plantear como única solución a estos problemas pasar muchas de las funciones estatales a manos de los particulares. Con ello queda oscurecida la vía alternativa de solución que es la transformación democrática y tecnicamente competente de las acciones e instituciones estatales.

Muchas de las características actuales de la acción estatal se derivan directamente del régimen político mexicano: presidencialista, de partido de Estado y dominación corporativa sobre la sociedad. La precondición de la transformación del 
Estado y del quehacer público es, por ello, la destrucción del actual régimen político y la construcción de otro basado en la democracia política y libre de la dominación corporativa. Sin embargo, para construir una nueva práctica pública se requiere, además, impulsar una serie de cambios concretos que garanticen nuevas relaciones de poder entre la sociedad civil y el Estado; mecanismos efectivos de regulación y control sobre la actividad pública; funcionários públicos honestos y preparados para realizar sus tareas y recursos suficientes y distribuidos con un criterio de equidad.

Un sistema de competencia electoral entre las expresiones partidarias de las distintas fuerzas sociales y políticas sería en las condiciones de México un mecanismo de redistribución de poder entre el Estado y la sociedad organizada ya que los proyectos partidarios tendrían que someterse al voto popular. Asimismo, una distinta distribución de facultades y obligaciones entre el poder ejecutivo, legislativo y judicial permitiría una mayor injerencia ciudadana en la conducción del Estado. Sin embargo, para el tema que nos ocupa resulta necesario ir más allá de la democracia electoral y una nueva división de poderes y proponer mecanismos específicos que viabilicen los cuatro puntos arriba señalados.

La estructuración del Estado mexicano confiere a la burocracia política un poder extraordinario que, en las condiciones actuales de ruptura del pacto social de la Revolución Mexicana, impide que la correlación de fuerzas en la sociedad se exprese en las instituciones públicas. Asimismo, tanto por su proceso de formación histórica como por la agudización de las contradicciones socio-políticas generales e intrainstitucionales la alta burocracia se ha automatizado a tal grado que se puede hablar del surgimiento de un "sujeto burocrático". ${ }^{73}$ Para romper el poder burocrático 
extraordinario y lograr la democratización de las instituciones es preciso que la correlación de fuerzas en la sociedad se expresa en ellas y, además, construir una nueva correlación de fuerzas institucional.

El poder burocrático se basa fundamentalmente en el control sobre los procesos de toma de decisiones y los recursos estatales. Es por ello necesario instrumentar mecanismos que disminuyan la discrecionalidad de la alta burocracia y la obligue a sujetarse a lineamientos generales de política fijados de manera democrática; a compartir la toma de decisiones con los involucrados en los problemas específicos (trabajadores y consumidores) y a someter sus acciones a una evaluación sistemática realizada por la sociedad organizada.

Uno de estos mecanismos sería establecer un sistema con cuerpos de planeación democrática, no solo de nombre, que fije los lineamientos generales de política sanitaria y los objetivos de transformación sujetándolo a la aprobación del poder legislativo. Además estos cuerpos democráticos tendrían la facultad y obligación de evaluar y dar a conocer sistematicamente los reaultados de los programas en función de la solución de problemas o los cambios reales logrados y no con base en las acciones realizadas.

Si se busca construir una nueva correlación de fuerzas que se exprese en las instituciones estatales es, además, preciso basar el proceso de planeación en el concepto de planeación estratégica en la formulación de Testa ${ }^{74}$ ya que contempla como elemento central el problema del poder institucional en sus vertientes técnico, administrativo y político. Así, define la "política" como una propuesta de repartición del 
poder y la "estrategia" como la forma de poner en práctica la política. Plantear el problema con este enfoque pone en el centro una concepción de la transformación como conflicto entre fuerzas sociales y políticas y permite pensar las implicaciones de distintas estrategias en términos de fortalecimiento o debilitamiento de estas fuerzas. ${ }^{75}$

En el marco de la planeación general es, asimismo, necesario desarrollar la planeación específica, regional y local, a cargo de instancias descentralizadas, representativas y con poder real apoyadas con la información necesaria para la toma de decisiones. O sea, habría que instrumentar sistemas locales de información construidos de tal modo que proporcionen información oportuna y centrada en la medición de impacto. ${ }^{76}$

5) Descentralización democrática e igualitaria

Otro medio para transformar la acción pública sería un proceso de descentralización igualitária y democrática distinta a la actualmente en marcha. Este proceso necesariamente tendría que abarcar todas las instituciones incluidas en la Secretaria de Seguridad Social y Salud para preparar su integración ulterior en el Servicio Unico de Salud. Por otra parte, en el actual esquema se descentralizan los servicios a las entidades federativas y no a los municipios como en las propuestas que tienen como uno de sus ejes centrales la democratización. ${ }^{77}$ Desde este ángulo la descentralización al municipio sería lo mejor pero significa problemas particularmente 
para los municipios pequeños que tienen que ser resueltos definiendo claramente la relación federación-estado-municipio.

En las distintas experiencias de descentralización se han detectado varios tipos de problemas que dificultan que ésta resulte igualitaria y democrática. ${ }^{78} \mathrm{El}$ primer tipo de problemas se refiere a la cuestión de la igualdad y dice relación, por un lado, con el contenido y calidad de los servicios y, por el otro, con los esquemas de financiamiento. Al respecto habría que garantizar que la descentralización no se convierta en el pretexto de proporcionar sólo atención primaria selectiva a los pobres en el subsistema público de población abierta ${ }^{79}$ ya que lo deforma y aleja del esquema de servicios delas instituciones de seguridad social.

Dado que la diferenciación en el tipo y calidad de los servicios se hace con la justificación de la escasez de recursos es necesario manejar esquemas de financiamiento regidos por criterios redistributivos nacionales e interinstitucionales. $O$ sea, no caben esquemas basados exclusivamente en la recaudación local que tienden a reproducir ampliadamente la desigualdad entre estados y municipios pobres y ricos.

Un segundo tipo de problemas se relaciona con cómo lograr un proceso efectivo de democratización, ya que muchas de las experiencias de "participación popular" bajo la forma de comités de salud son negativas. Por ello, habría que establecer organismos de gestión con representantes de elección directa, de los partidos, de las organizaciones sociales y de las instituciones involucradas con capacidad de toma de decisiones, asignación de recursos y evaluación de programas. Es decir, estos organismos deben tener las suficientes facultades para poder abordar 
los problemas específicos del nivel local y la obligación de responder de sus acciones ante sus representados. Sin embargo, la capacidad de toma de decisiones descentralizadas no significa el derecho de apartarse de los lineamientos generales de política sanitaria.

Lograr una real democratización, en las actuales condiciones de México, pasa necesariamente por romper las estructuras locales de control y combatir las prácticas autoritárias y clientelistas. Asimismo, es preciso idear mecanismos para proporcionar los elementos de juicio necesarios a los miembros de los organismos de gestión para evitar que se les controle con un manejo excluyente del conocimiento técnico-científico. Por otra parte, es preciso que estos organismos funcionen de tal manera que no se ahogen en los detalles de la gestión sino puedan dedicar su esfuerzo a trazar los lineamientos de los aspectos principales.

El tercer tipo de problemas tiene que ver con la necesidad de desarrollar la capacidad técnica y administrativa local y estatal ya que la incompetencia en estos aspectos ha causado desastres en los de por sí débiles servicios periféricos. De poco sirve incrementar los recursos y democratizar la gestión si los ejecutores de los programas ignoran cómo hacerlos funcionar. El problema no es sencillo porque se busca simultáneamente maximizar la competencia técnica y administrativa y minimizar el predominio del poder técnico-administrativo; ecuación que sólo se puede cuadrar con el desarrollo de una nueva cultura de servicio público y de conciencia sanitaria de los usuarios y sus representantes. 
Por último habría que garantizar que la descentralización no lesiona los derechos sindicales de los trabajadores con la pulverización de los sindicatos y la desaparición de los contratos colectivos nacionales. Junto a ello está planteada la necesidad de democratizar a fondo los sindicatos ya que la democratización sindical no es sólo una reivindicación legítima de los trabajadores sino además una condición de la descentralización democrática que requiere de una representación auténtica de los trabajadores de salud.

6) Transformación institucional y revalorización del trabajo

Junto al proceso de integración del servicio único existe la necesidad inmediata de reconstruir y fortalecer las instituciones en cuanto espacios concretos de trabajo y de producción de servicios para revertir su deterioro y mejorar la calidad de los servicios. Esto involucra movilizar la capacidad colectiva y creativa de los trabajadores desalud; democratizar la gestión; defender los derechos del usuario; lograr que los servicios tengan capacidad de resolución de los problemas planteados a cada nivel y dotarlos de los recursos necesarios.

Por la multiplicidad de problemas y la profundidad de las transformaciones requeridas en las instituciones de salud el proyecto alternativo de. politica sanitaria tiene que descansar sobre la movilización de la capacidad colectiva y creativa de sus trabajadores. Para que ello sea posible es necesario poner las bases para algo que se puede llamar un "nuevo pacto institucional". Sin este acuerdo básico los mejores 
programas pueden fracasar al topar con la resistencia de los trabajadores. ${ }^{80}$ Los elementos centrales de ese pacto son recuperar las condiciones económicas y laborales de los trabajadores, recalificar el trabajo institucional y democratizar la gestión de los centros de trabajo.

La recuperación de las condiciones económicas de los trabajadores significa revertir, en el corto plazo, la pérdida salarial de la última década, ya que no es posible pedir un mayor esfuerzo y renumerarlo peor. Asimismo, es necesario proporcionar los medios indispensables para la realización el trabajo en función de las tareas que se suponen deben desarrollarse en cada centro de trabajo. Sin ello, no hay posibilidad de producir servicios de calidad. Sin embargo, el elemento mas importante es la recalificación del trabajo que significa un proceso permanente de actualización y capacitación pero ante todo la reorganización del trabajo para incrementar el control y la capacidad de toma de decisiones de los trabajadores sobre cómo realizar sus tareas. No hay ninguna de movilizar la capacidad y creatividad de los trabajadores para la solución de los problemas si simultáneamente se pretende imponer sistemas verticales y burocráticos de control y normatización.

La democratización de la gestión de las instituciones como espacios concretos de trabajo y prestación de servicios es parte del proceso general de democratización dela acción pública. Así, significa establecer organismos de gestión con participación efectiva de los trabajadores y usuarios armonizando sus funciones con las de las otras instancias democráticas. Una cuestión que requiere particular atención son los criterios para nombrar democraticamente los cuadros directivos de las instituciones y normar su actuación. Deben ser incluidos, por lo menos, la 
capacidad profesional y la obligación de instrumentar las políticas fijadas por los organismos de gestión y responder ante ellos. Asi mismo hay que emprender un combate enérgico contra las distintas formas de corrupción y abuso de poder sometiendo el manejo institucional y de fondos públicos a la fiscalización de los organismos de gestión democrática apoyadas con auditorias sistemáticas.

El mejoramiento de la calidad del servicio debe abarcar por lo menos dos cuestiones. ${ }^{81}$ Una es que habría que lograr un nivel aceptable de capacidad de resolver la problemática específica que se presenta en cada uno de los centros de atención. Esto requiere de una definición precisa de los programas, de la infraestructura necesaria y de la preparación adecuada del personal para llevar adelante el trabajo. La otra es que debe haber un concepto claro de derechos del usuario, ya que actualmente tiende a prevalecer la indefensión de los pacientes en el ámbito institucional.

7) Incremento de recursos y redistribución de la riqueza social

El principal argumento esgrimido para imprimir el sello neoliberal a la política social es que la escasez de recursos ha obligado a realizar los recortes del gasto social, focalizarlo en los grupos más pobres y responsabilizar crecientemente a la sociedad (léase cada quien) de la satisfación de las necesidades de salud. Con ello los servicios públicos se han convertido en un instrumento marginal de la redistibución global de la riqueza social ya que casi no impactan la distribución, extremadamente 
asimétrica, del ingreso disponible entre ganancias y renumeraciones. ${ }^{82}$ Es más, al mantener un superávit primario en las finanzas públicas para garantizar la máxima prioridad de la política económica -el pago del servicio de la deuda- la población trabajadora ni siquiera recupera bajo la forma de servicios públicos lo que pagó en ISR e IVA. Así, la recaudación en estos rubros fue seis veces mayor que el gasto social. ${ }^{83}$ Queda claro, pues, que la actual política de mantener el gasto en salud muy por debajo de las normas internacionales no es una necesidad ineludible sino una opción consciente.

La propuesta respecto al financiamiento de la política sanitaria alternativa tendría que adelantar medidas que incrementan el gasto en salud sustancialmente; que tienen un efecto redistributivo de la riqueza social hacia los trabajadores y que permiten avanzar hacia la unificación del sistema de financiamento como prerequisito de la integración del Servicio Unico de Salud. Una política global alternativa, ${ }^{84}$ basada en el decremento del pago del servicio de la deuda y la recuperación salarial, permitiría un aumento rápido en el presupuesto de salud. Ocurre así porque redundaría en un incremento en el gasto federal programable, una parte del cual podría ser redirigido al gasto social con la ventaja añadida de que una mayor oferta de servicios públicos no necesariamente es inflacionaria. Por otra parte, una política de recuperación salarial incrementaría automaticamente los ingresos de los institutos de seguridad social ya que son directamente proporcionales al salario de los asegurados. En términos de la distribución del ingreso tendría el efecto de bajar las ganacias especulativas de los rentistas y recanalizarlas para el salario indirecto de los trabajadores. 
Sin embargo, para poder destinar suficientes recursos para la universalización de servicios públicos de buena calidad y convertirlos en un mecanismo real de redistribución de la riqueza social habría que revisar a fondo la política distributiva particularmente en su aspecto de recaudación. Los dos mecanismos más importantes para incrementar la recaudación y dirigir una parte mayor al gasto de salud podrían ser un incremento sustancial en las contribuciones patronales a la seguridad social e impuestos especiales.

El incremento de las contribuciones a la seguridad social ha sido uno de los pilares de la expansión y universalización de los beneficios sociales en el periodo de posguerra. Así por ejemplo, en Alemania Federal este rubro se incremento $100 \%$ como porcentaje del PIB entre 1950 y 1985 mientras el dato correspondiente de los impuestos fue $20 \%{ }^{85}$ En Suecia se reestructuró en tan sólo diez años, de 1975 a 1985 , el financiamento del gasto social público incrementando la parte pagada por los patrones del $24 \%$ al $48 \% .^{86}$ Para apreciar el margen para aumento que hay en las contribuciones patronales en México se puede mencionar que hoy las cuotas patronales para seguridad social y vivienda no exceden un $18 \%$ sobre los salarios pagados mientras que en Suecia son un $67 \%$.

Por otra parte, habría que analizar cuál es la base más apropiada para fijar la contribución patronal, ya que, por ejemplo en Brasil, no es sólo el monto de los salarios sino también de las ganacias y de la facturación. ${ }^{87}$ La propuesta de incrementar las contribuciones patronales de seguridad social pagadas por los empleadores tiene, además, el atractivo de que significa una transferencia de las 
ganancias a los salarios en la suposición de que no sean cargadas al precio final del producto.

En el rubro de impuestos especiales se podría gravar la venta de servicios privados de salud e incrementar los impuestos de alcohol y tabaco. Lo primero se justifica por los altos niveles de ganancia en la producción de los servicios privados. ${ }^{88}$ El aumento en los impuestos de alcohol y tabaco se podría instrumentar por varias vías; una sería prohibir su publicidad y establecer como impuesto un porcentaje equivalente a los gastos publicitarios lo que no cambiaría el precio final o, alternativamente, fijar un impuesto del $100 \%$ sobre su venta que además satisfacería a aquellos que creen que el precio desincentiva el consumo.

En el marco de la integración de la Secretaría de Seguridad Social y Salud sería posible constituir un Fondo Unico de Servicios de Salud juntando la aportación federal, la parte correspondiente a los servicios de salud de las cuotas de seguridad social, los impuestos especiales y otros ingresos como los de la Lotería Nacional, etc.,siguiendo un esquema semejante al brasileño. ${ }^{89}$

En el marco de un aumento sustancial y creciente del gasto en salud sería posible instrumentar esquemas de financiamento que implican ritmos de crecimiento más rápidos en áreas de mayor rezago sin sacrificar el crecimiento del gasto destinado al conjunto de los servicios públicos. Es decir, una alternativa con estas características prioriza una expansión general de los servicios públicos y, en este marco, busca resolver en el corto plazo los principales rezagos, lo que es un planteamiento contrario 
a la actual política que restringe los recursos públicos y, luego, focaliza el menguado gasto en los grupos más pobres.

\section{REFERENCIAS BIBLIOGRÁFICAS, CITACIONES Y NOTAS}

01. GEORGE, V. \& WILDING, P. Ideology and social welfare. London. Rotledge and Kegan Paul, 1985. p.19-43.

02. TAYLOR-GOOBY, P. Welfare, hierarchy and the "new right": the impact of social policy changes in Britain, 1979-89. Int. Sociol., 4(4): 431-46, 1989.

03. GEORGE-WILDING op. cit., p. 44-68

04. Ibid, p. 67

05. Ibid, p. 69-94

06. ESPING-ANDERSEN, G. Politics against markets. Princeton, Princeton University Press, 1985 p.148

07. Ibid, p. 159-160

08. MARSAHLL, T.H. Class citizenship and social development. Chicago, University of Chicago Press, 1964.

09. ESPING-ANDERSEN op. cit.

10. Ibid, p. 191-243

11. Ibid, p. 71-113

12. TAYLOR-GOOBY, op. cit. 
-- NAVARRO, V. El estado de bienestar y sus efectos redistributivos. IN Congreso de Salud Pública y Administración Sanitaria $2^{\circ}$, Madrid, 1987.

13. THERBORN, G. \& ROEBROEK, J. The irreversible welfare state. Int. J. Health Servi. 16 (3):332, 1986.

-- OFFE, C. Contradictions of the welfare state. London, 1984.

14. NAVARRO, V. Why some countries have national health insurance, others have national health services and the U.S. have neiter. Soc. Scl. Med. 28(9):887, 1989.

15. DAVIS, M. Prisoners of the american dream. London, Verso, 1986.

16. Véase por ejemplo:

-- MARKLUND, S. Paradise lost?. Lund, Arkiv, 1988.

-- NAVARRO, V. El estado de bienestar... op. cit.

17. CONSTITUCIÓN POLÍTICA DE LOS ESTADOS UNIDOS MEXICANOS. México, CFE, 1989. Artículos 3, 4 y 123

18. Ibid

19. Ibid, artículo 3

20. FLEURY, S. Em defensa da seguridade social. Saúde em Debate. (26):33-6, 1989.

21. Plan Nacional de Desarrollo: 1989-1994. México. Poder Ejecutivo Federal, 1989.

22. La Jornada 13/3, 1990

23. PNUD: Proyecto regional para la superación de la pobreza. México, 1989. Apud Provencio, E. El nuevo plan y la política social. Cuad. Nexos (13), 1989.

24. SÁNCHEZ BAYLÓN, T. La nueva legislación laboral anunciada por el régimen en dos proyectos de nación. México, STUNAM, 1989.

25. ROJAS, C. La solidaridad una urgencia social, ponencia presentada ante el Centro de Estudios México-Americanos. La Jornada, 25-26/1, 1990.

- Provencio op. cit. 
26. Ley General de Salud. México, 1984, Título Segundo.

27. Primer informe de Gobierno. Anexo estadístico. Poder Ejecutivo Federal. México, 1989.

28. Ibid

29. Sistema de Cuentas Nacionales de México. México, SPP-INEGI, 1988.

30. SOBERÓN, G. et al: La salud en México: fundamentos del cambio estructural. México. Fondo de Cultura Económica, 1988, p. 109.

31. Ibid, p. 116

32. Ibid, p. 241

33. Ley del Seguro Social. México, Ed. Porrúa, 1990.

34. Ibid, p. 374

Actualmente la composición de la Asamblea es: 6 por la Concamin, 4 por la Concanaco, 7 por la CTM, 2 por la CROM y 10 por el Gobierno Federal incluyendo el Director General del IMSS y el Secretario de la SSA.

35. MÁRQUEZ, P. V. \& ENGLER, T. Crisis y salud: retos para los 90. Educ. Méd. Salud, 24 (1): 7-26 1990.

36. Véase por ejemplo:

-- CONTRERAS, R. Salud p'ublica, privada y solidaria en el Chile actual. Santiago. PET, 1986.

-- HAIGNERE, S.S. The aplication of the free markett model in Chile. Int. J. Health Serv. 13 (3):389, 1986.

-- BELLO, J. Política sanitaria Argentina 1976-1981. Cuad. Méd. Soc. (23), 1983.

-- BELMARTINO, S. \& BLOCH, C. Las política de salud y el bienestar social en Argentina. Est. Sociol., 2(5/6):277, 1984.

-- FLEURY, S. De la retótica a la realidad: la política de salud en la transición conservadora.

Cuad. Méd. Soc.(48):14-87, 1989. 
37. OCHOA, M. Política de gasto en el sector salud (1977-1986) In: Almada,I. Salud y crisis en México. México, Siglo XXI, 1990. p: 274-300.

38. Programa Nacional de Salud. México. SSA, 1984.

39. LÓPEZ ARELLANO, O. la política de salud en México. México, 1990. ( Tesis de Maestría en Medicina Social).

40. SORIA, V. Excélsior. México, 26 de octubre, 1989.

41. GRODOS, D. De Béthuna X: las intervenciones sanitarias selectivas. Cuad. Méd. Soc. (46):71-85, 1989.

42. Plan nacional de desarrollo, op. cit.

43. Diario Oficial México, 30 de agosto 1983.

44. SOBERÓN, op, cit. p:103-40

45. Véase por ejemplo:

-- MENÉNDEZ, E. Continuidad y descontinuidad del proyecto sanitarista mexicano: crisis y reorientación neoconservadora en Almada, op. cit. p:221-45

-- LÓPEZ ARELLANO op. cit.

46. RUIZ DE CHÁVEZ, M.; MÁRQUEZ, M.; OCHOA, M. E I enfoque de la salud como sector social y económico. México. SSA, 1988.

47. Primer Informe de Gobierno, op. cit.

48. Op. cit.

49. RODRÍGUEZ, C. La respuesta social: los trabajadores de la salud, en Almada, op. cit. p:301-32.

50. Ibid

51. RUÍZ DE CHÁVEZ-MÁRQUEZ-OCHOA op. cit.

52. Sistema de Cuentas Nacionales, Tomo III, op. cit. 
53. Sistema de Cuentas Nacionales, op. cit., cuadro 190 y 191 y los datos de RUÍZDE CHÁVEZ et al., op. cit., p 43 respecto a la distribución del excedente de producción entre el sector público y privado.

54. Ley del Seguro Social, op. cit., artículo 97 fracción III.

55. Situam: seguro familiar de gastos médicos mayores Bol. Inf. México, 1990.

56. ZEPEDA, M. E periodo legislativo de fim de año. Coyuntura n. 0, 1990.

57. CORDEIRO, H. \& ZAVALETA, H. Análisis de la práctica médica actual en América Latina: alternativas y tendencias. In: Organización Panamericana de la Salud. Análisis de las organizaciones de salud. Washinton DC, 1987.

58. Véase por ejemplo:

-- PRD. Documentos Básicos. México, 1989.

-- Ponencia marco: Política social, I Foro de Economía del PRD, México, 1990.

59. Véase por ejemplo:

-- BREILH, J. Epidemiología: economía, medicina y política. México, Fontamara, 1987.

-- LAURELL, A. C. \& NORIEGA, M. La salud en la fábrica. 1989.

60. Véase por ejemplo:

--SONIS, A. Salud, medicina y desarrollo socio-económico. Buenos Aires, Universidad de Buenos Aires, 1968.

61. GARDELL, B. Workers' participation and autonomy: a multilevel approach to democracy at the workplace. Int. J. Serv., 12 (1): 527-58, 1982.

62. NARRO, J. et al. Evolución reciente de la mortalidad en México. Rev. Comércio Ext., 34 (7): 636-46, 1984.

63. Véase por ejemplo:

-- ECHEVERRÍA, M. Enfermedades de los trabajadores y crisis económica. Santiago, PISPAL, 1983. 
-- KARASEK, R. et al. Job decision latitude, job demands and coronaryheart disease. Amer. J. Public Health, 71: 694-705, 1981.

64. Véase por ejemplo:

-- DAHLGREN, G. \& DIDERICHSEN, F. Strategy for equity in health: a report from Sweden. Int. J. Health Serv., 16(4):517, 1986.

-- KARASEK, R. \& THEORELL, T. Healthy work: stress, productivlty and the reconstruction of working life. New York, Basic Books, 1990.

65. Véase por ejemplo:

- FLEURY, S. Reforma sanitaria. So Paulo, ABRASCO, 1989.

-- BERLINGUER, G. Gli anni difficile della riforma sanitaria. Bari, De Donato, 1982.

66. FLEURY, S. De la retórica... op. cit.

67. Véase por ejemplo:

- NAVARRO, V. Why some countries... op. cit.

-- WHITIES, D. \& SALMON, J. W. The propietarization of health care and the under development of the public sector.Int. J. Health Serv., 17(1):47-63, 1987.

68. NAVARRO, V. The arguments against a national health program:science or ideology. Int. J. Health Serv., 18(2): 179-89, 1988.

69. Ibid

70. WOOLHANDLER, S. \& HIMMELSTRAND, D. Free care: a quantitative analysis of health and cost effects of a national health program for the US. Int. J. Health Serv., 18 (3):393-400, 1988.

71. RUÍZ DE CHÁVEZ et al. op. cit. p.43.

72. WAITAKIN, H. La explotación de la enfermedad en la sociedad capitalista. Nueva Imagen, 1981.

73. KENT, R. La organización universitária y la masificación. Sociológica, 2 (5): 73-119, 1987. 
74. TESTA, M. Estrategia, coherencia y poder en la propuesta de salud. Cuad. Méd. Soc., 38/39: 1987.

75. CHOMY, A. El enfoque estratégico para el desarrollo de recursos humanos. Educ. Méd. Salud, 24 (1): 27-51, 1990.

76. ANDERSSON, N.; MARTÍNEZ, E.; VILLEGAS, A.; RODRÍGUEZ, I. Vigilancia epidemiológica y planeación descentralizada. Salud Pública México, 31(4): 493-502, 1988.

77. Plataformas de saúde (PT-FBP,PSD,PCB, PMDB) Saúde em Deb.(26): 8-27, 1989.

78. BELmARTINO, S. Políticas sociales: discusión de una alternativa. Cuad. Méd. Soc., (49/50):5-12, 1989.

79. Véase por ejemplo:

-- GRODOS- BÉTHUNA, op. cit.

-- MENÉNDEZ, op. cit.

80. Véase por ejemplo:

-- FLEURY et al. Reforma sanitaria, op. cit.

-- TORRESGOITIA, J. Democracia y salud: la experiencia de Bolivia. Santiago, ILPES/UNICEF, 1987.

81. Plataformas de saúde, op. cit.

82. Primer Informe de Gobierno, op. cit., p.23

83. Ibid, p. 28 y31.

84. Véase por ejemplo:

-- CLARKE, R. Una política económica para el corto plazo. Cuad. Políticos (57): 43-52, 1989.

85. BAILLET, A. \& ZIMMERMANN, H. La evolución reciente del sistema impositivo de México y Alemania. México, F.F. EBERT. 1989. p 30.

86. MARKLUND, op. cit., $p$ 87-88 
87. MEDICI, A. C. O orçamento da seguridad social em 1989. Saúde Deb. (25):21-4, 1989.

88. RUÍZ DE CHÁVEZ, op. cit., p. $42-5$ y cuadro 4 y 5.

89. Ibid, y FLEURY Em defesa da seguridade social. op. cit. 